THU0409

\section{MANAGEMENT OF SYSTEMIC SCLEROSIS (SSC) RELATED DIGITAL ULCERS (DU) IN EXPERT TERTIARY CENTRES: RESULTS FROM THE ANALYSIS OF THE MULTICENTRE OBSERVATIONAL REAL-LIFE DESSCIPHER/EUSTAR STUDY}

J. Blagojevic ${ }^{1}$, G. Abignano ${ }^{2}$, Y. Allanore ${ }^{3}$, J. Avouac ${ }^{3}$, L. Cometi ${ }^{1}$, L. Czirják ${ }^{4}$, C. Denton ${ }^{5}$, O. Distler ${ }^{6}$, M. Frerix, S. Guiducci ${ }^{1}$, D. Huscher ${ }^{8}$, V.K. Jaeger ${ }^{9}$, V. Lóránd ${ }^{10}$, B. Maurer ${ }^{6}$, S. Nihtyanova ${ }^{5}$, G. Riemekasten ${ }^{11}$, E. Siegert $^{8}$, G. Valentini ${ }^{12}$, S. Vettori ${ }^{12}$, U.A. Walker ${ }^{9}$, U. Müller-Ladner ${ }^{7}$, F. Del Galdo ${ }^{2}$, M. Matucci-Cerinic ${ }^{1} .{ }^{1}$ Department of Experimental and Clinical Medicine, University of Florence, Department of Geriatric Medicine, Division of Rheumatology AOUC, Florence, Italy; ${ }^{2}$ Leeds Institute of Rheumatic and Musculoskeletal Medicine, University of Leeds and NIHR Leeds Biomedical Research Centre, Leeds Teaching Hospitals NHS Trust, Leeds, UK; ${ }^{3}$ Department of Rheumatology, University of Paris Descartes, Paris, France; ${ }^{4}$ Department of Rheumatology and Immunology, University of Pécs, Pécs, Hungary; ${ }^{5}$ Department of Rheumatology, University College London, Royal Free Hospital, London, UK; ${ }^{6}$ Department of Rheumatology, University Hospital Zurich, Zurich, Switzerland; ${ }^{7}$ Department of Rheumatology and Clinical Immunology, Justus-Liebig University Giessen, Kerckhoff Clinic Bad Nauheim, Giessen/Bad Nauheim; ${ }^{8}$ Department of Rheumatology and Immunology, Charité University Hospital, Berlin, Germany; ${ }^{9}$ Department of Rheumatology, University of Basel, Basel, Switzerland; ${ }^{10}$ Department of Rheumatology and Immunology, University of Pécs, Pécs, Hungary: ${ }^{11}$ University Schleswig-Holstein Lübeck, Lübeck, Germany;

${ }^{12}$ Department of Rheumatology, Second University of Naples, Naples, Italy

Background: In SSc, the management of DU is a real clinical challenge. It includes the use of vasoactive and vasodilating drugs, but no comparative studies between agents are available. DeSScipher was the first European multicentre observational study with the aim to decipher the optimal management of SSc.

Objectives: To assess in expert centres the current therapeutic strategy for the management of SSc related DU.

Methods: Baseline demographic and clinical characteristics of patients enrolled in the DeSScipher/EUSTAR ulcer study and detailed data regarding DU were analysed.

Results: There were 1823 patients enrolled in this study. 277 (15.2\%) presented DU at the enrolment visit, $628(34.4 \%)$ had previous DU and $918(50.4 \%)$ had never experienced DU. Patients with DU (current or previous) were more frequently anti-Scl70 positive, had more frequently the diffuse cutaneous subset $(40.8 \%$ vs $26.7 \% \quad(p<0.000))$, gastro-esophageal symptoms $(70 \%$ vs $63.4 \%$ $(\mathrm{p}=0.002))$ and lung fibrosis on lung $\mathrm{Rx}$ or HRCT $(65.7 \%$ vs $54 \%(\mathrm{p}=0.001))$ compared to patients without DU. There were no significant differences in the prevalence of pulmonary hypertension (7.3\% patients with DU vs $5.3 \%$ patients without $\mathrm{DU}, \mathrm{p}=0.87$ ). Treatment of patients with and without $\mathrm{DU}$ is shown in table 1 .

Abstract THU0409 - Table 1. Treatment of patients with and without DU

\begin{tabular}{lcc}
\hline & $\begin{array}{c}\text { Patients with DU (current or } \\
\text { previous) 905 patients }\end{array}$ & $\begin{array}{c}\text { Patients without DU (never } \\
\text { developed) } 918 \text { patients }\end{array}$ \\
\hline Calcium channel & $601(66.4 \%)$ & $704(76.9 \%)^{\star}(\mathrm{p}<0.000)$ \\
blockers & $199(22 \%)$ & $41(4.5 \%)^{\star}(\mathrm{p}<0.000)$ \\
Bosentan & $120(13.3 \%)$ & $57(6.2 \%)^{\star}(\mathrm{p}<0.000)$ \\
Sildenafil & $85(9.4 \%)$ & $15(1.6 \%)^{\star}(\mathrm{p}<0.000)$ \\
Bosentan+Sildenafil & $306(33.8 \%)$ & $74(8.1 \%)^{\star}(\mathrm{p}<0.000)$ \\
lloprost iv in the last & $48(5.3 \%)$ & $97(10.6 \%)^{\star}(\mathrm{p}<0.000)$ \\
3 months & & $560(61 \%)$ \\
No vasodilating & $482(53.3 \%)$ & \\
therapy & &
\end{tabular}

Information on recurrent DU were available for $779(86.1 \%)$ of patients with DU. Treatment of patients with and without recurrent DU is shown in table 2.

Abstract THU0409 - Table 2. Treatment of patients with and without recurrent DU

\begin{tabular}{lcc}
\hline & $\begin{array}{c}\text { Patients with recurrent DU } \\
(428)\end{array}$ & $\begin{array}{c}\text { Patients without recurrent DU } \\
(351)\end{array}$ \\
\hline Calcium channel blockers & $\mathbf{2 5 8 ( 6 0 . 3 \% )}$ & $\mathbf{2 5 5}(\mathbf{7 2 . 7 \%})^{\star}(\mathbf{p}<\mathbf{0 . 0 0 0})$ \\
Bosentan & $105(24.5 \%)$ & $70(19.9 \%)$ \\
Sildenafil & $58(13.6 \%)$ & $45(12.8 \%)$ \\
Bosentan+Sildenafil & $\mathbf{3 2 3 ( 7 5 . 5 \% )}$ & $\mathbf{8 7}(\mathbf{2 4 . 7 \%})^{\star}(\mathbf{p}<\mathbf{0 . 0 0 0 )}$ \\
lloprost iv in the last & $\mathbf{2 1 2 ( 4 9 . 5 \% )}$ & $\mathbf{7 7}(\mathbf{2 2} \%)^{\star}(\mathbf{p}<\mathbf{0 . 0 0 0 )}$ \\
3 months & $27(6.3 \%)$ & $14(3.9 \%)$ \\
No vasodilating therapy^ & $222(51.9 \%)$ & $226(64.3 \%)$ \\
Immunosuppressants & &
\end{tabular}

Conclusions: $90 \%$ of SSc patients were on vasodilating and/or vasoactive treatment regardless of the history/presence of DU. Recurrent DU were treated aggressively, using in $75 \%$ of cases Bosentan and Sildenafil combination therapy. Our data indicate frequent use of Sildenafil and Bosentan for DU management in specialised centres, especially for recurrent DU.

Disclosure of Interest: None declared

DOI: 10.1136/annrheumdis-2018-eular.3771

\section{THU0410 SURVIVAL OF PATIENTS WITH MUSCLE BIOPSY PROVEN IDIOPATHIC INFLAMMATORY MYOPATHY BASED ON A STUDY IN A TERTIARY UNIVERSITY CENTRE}

K. Gulyás ${ }^{1}$, E. Pál ${ }^{2}$, T. Minier ${ }^{1}$, T. Berki ${ }^{3}$, L. Czirják ${ }^{1}$, C. Varjú ${ }^{1} .{ }^{1} U P M S$

Department of Rheumatology and Immunology, ${ }^{2}$ UP MS Department of Neurology,

${ }^{3}$ UP MS Department of Immunology and Biotechnology, Pécs, Hungary

Background: Idiopathic inflammatory myopathies (IIM) are characterised by muscle weakness due to muscle inflammation, various organ involvements and the presence of certain specific autoantibodies.

Objectives: To assess survival and characterise subsets based on muscle biopsy and myositis specific autoantibodies.

Methods: Eighty-two patients with muscle biopsy proven IIM were included in the study. Muscle biopsy was reevaluated and cathegorized by the same investigato (EP). All cases had myositis specific (MSA) and myositis associated (MAA) antibody tests. The MSAs and MAAs (Jo-1, PL-7, PL-12, Mi-2, SRP, Pm-Scl, Ku, ribo somal, AMA-M2) were tested with Western-blot.

Dermatomyositis/DM/, polymyositis/PM/, juvenile PM/DM, inclusion body myositis/lBM/, overlap myositis/OM/ and immune mediated necrotizing myopathy/ IMNM/were identified based on clinical data, immunserology and muscle biopsy. Patients were treated with glucocorticoids/cytostatics, interstitial lung disease was treated with pulse cyclophosphamide in 15/43 cases. Survival analysis was perfomed by Kaplan Meier test.

Results: Fifty-nine women and 23 men with a mean age of $49.3 \pm 14.6$ years were included. Mean follow-up of the patients was $7.5 \pm 4.5$ years. Interstitial lung disease (ILD) $(51.2 \%)$, arthritis (51.2\%), Raynaud's phenomenon $(42.7 \%)$, skin symptoms $(45.1 \%)$, dysphagia $(24.4 \%)$ and significant cardiac involvement $(15.9 \%)$ were the most prevalent disease manifestations. 15 cases were associated with malignancies.

The distribution of myositis subsets is as follows: $26.8 \%(n=22)$ PM, 30.5\% $(n=25)$ DM, 1.2\% $(n=1)$ juvenile PM/DM, 8.5\% $(n=7)$ IBM, 22\% $(n=18)$ OM, and $11 \%$ $(\mathrm{n}=9)$ IMNM.

Malignancy was most frequently associated with IMNM (7 out of 9 patients).

Altogether 18 patients died from which 15 deaths can be connected to myositis related events. Eight patients died of malignancies (4 in the IMNM, 2 in the PM and 2 in the DM group), 5 patients due to cardiac events (heart failure, arrythmia), 2 due to lung fibrosis and 3 by unknown causes. The worst prognosis with a 10 year survival of $31 \%$ was in the IMNM subgroup $(p<0.01)$, followed by patients with PM (68\%), IBM (84\%) OM (85.1\%) and DM (85.3\%). Mi-2 positive patients had a favourable prognosis with a 10 year survival of 100 . Patients with muscle histology corresponding with IMNM had the worst prognosis (10 year survival of $31.1 \%)$, followed by PM (76\%), DM and IBM ( $85.7 \%$ each). Non specific muscle changes unclassifiable to any of the previous groups were associated with a relatively favourable prognosis (5 year survival of $80 \%)(p<0.01)$.

Patients with antisynthetase antibody-positivity had worse prognosis compared with patients with other antibodies or no identifiable antibodies (10 year survival of $55 \%, n=16)(p<0.05)$. When comparing patients with MSA or MAA, the worst prognosis was seen in patients with both MSA and MAA positivity (10 year survival of $35.6 \%, n=10$ ).

Conclusions: The worst survivals were seen in the IMNM and PM groups, due to the high frequency of the underlying malignancies and cardiac manifestations. Although ILD was the most frequent involvement, it was not a major determinant of outcome.

Disclosure of Interest: None declared

DOI: 10.1136/annrheumdis-2018-eular.2405

\section{THU0411 MYASTHENIA GRAVIS WITHOUT THYMIC PATHOLOGY AND POLYMYOSITIS: A RARE ASSOCIATION}

L. Castelnovo ${ }^{1}$, P. Faggioli ${ }^{1}$, A. Tamburello ${ }^{1}$, A.G. Gilardi ${ }^{1}$, A. Laria ${ }^{2}$, A.M. Lurati $^{2}$ K.A. Re ${ }^{2}$, D. Mazzocchi ${ }^{2}$, M.G. Marrazza ${ }^{2}$, A. Mazzone ${ }^{1} .{ }^{1}$ Medicina Interna, Asst Ovest Milanese - Ospedale Civile Di Legnano E Cuggiono, Legnano;

${ }^{2}$ Reumatologia, Asst Ovest Milanese - Ospedale Civile Di Legnano E Cuggiono, Magenta, Italy

Background: Myasthenia gravis(MG) is an autoimmune disease frequently associated with antibodies against the acetyl-choline receptor. These antibodies contribute to the characteristic defects in neuromuscular transmission. Inflammatory myopathies, as polymyositis(PM), are immune-mediated neuromuscular 